\title{
Prostaglandin D2 in Inflammatory Arthritis and Its Relation with Synovial Fluid Dendritic Cells
}

\author{
Mahin Moghaddami, ${ }^{1}$ Enzo Ranieri, ${ }^{2}$ Michael James, ${ }^{1}$ \\ Janice Fletcher, ${ }^{2}$ and Leslie G. Cleland ${ }^{1,3}$ \\ ${ }^{1}$ Arthritis Research Laboratory, Hanson Institute, SA Pathology, Adelaide, SA 5000, Australia \\ ${ }^{2}$ Genetics and Molecular Pathology, Women's \& Children's Hospital Campus, North Adelaide, SA 5006, Australia \\ ${ }^{3}$ Rheumatology Unit, Royal Adelaide Hospital, North Terrace, Adelaide, SA 5000, Australia
}

Correspondence should be addressed to Leslie G. Cleland; les.cleland@health.sa.gov.au

Received 19 December 2012; Revised 18 March 2013; Accepted 10 April 2013

Academic Editor: Eric F. Morand

Copyright (C) 2013 Mahin Moghaddami et al. This is an open access article distributed under the Creative Commons Attribution License, which permits unrestricted use, distribution, and reproduction in any medium, provided the original work is properly cited.

\begin{abstract}
Prostaglandin $(\mathrm{PG}) \mathrm{D}_{2}$ has been shown to be an active agent in the resolution of experimentally induced inflammation. This study was undertaken to determine the presence of $\mathrm{PGD}_{2}$ in chronic joint effusions and to explore the potential contributions of dendritic cells (DC) and monocytes to the intra-articular synthesis of $\mathrm{PGD}_{2}$. Synovial fluid (SF) was obtained from patients with inflammatory arthritis and knee effusions. $\mathrm{PGD}_{2}$ and $\mathrm{PGE}_{2}$ were detected in SF by ultrahigh-performance tandem mass spectrometry. Cellular fractions in SF were separated by density-gradient centrifugation and flow cytometry. The expression of hematopoietic prostaglandin D-synthase (hPGDS) and PGE-synthase (PGES) mRNA was determined by RT-PCR. Both PGD 2 and $\mathrm{PGE}_{2}$ were detected in blood and $\mathrm{SF}$, with $\mathrm{PGD}_{2}$ being more abundant than $\mathrm{PGE}_{2}$ in $\mathrm{SF}$. $\mathrm{mRNA}$ for hPGDS was more abundant in SF mDCs than SF monocytes $(P<0.01)$ or PB monocytes $(P<0.001)$. SF mDC expressed significantly more hPGDS than PGES. Expressions of $\mathrm{PGD}_{2}$ and hPGDS were inversely associated with serum C-reactive protein $(P<0.01)$ and erythrocyte sedimentation rate $(P<0.01)$. The findings suggest that synovial DCs may be an important source of hPGDS and that systemic disease activity may be influenced by actions of $\mathrm{PGD}_{2}$ in RA and other arthropathies.
\end{abstract}

\section{Introduction}

Cyclooxygenase (COX) metabolises arachidonic acid to prostaglandin $\mathrm{H}_{2}\left(\mathrm{PGH}_{2}\right)$ which is then converted to $\mathrm{PGE}_{2}$ and $\mathrm{PGD}_{2}$ via their respective synthases [1]. Synthesis of $\mathrm{PGE}_{2}$ is involved in inflammation, and mice deficient in PGE synthase had decreased pain responses, decreased delayedtype hypersensitivity, and suppression of collagen-induced arthritis [2]. Upstream suppression of PGE synthesis by inhibitors of COX-2 is thought to explain the analgesic effects of nonsteroidal anti-inflammatory drugs (NSAIDs), including the COX-2 inhibitors, on arthritis [3].

In contrast to proinflammatory $\mathrm{PGE}_{2}, \mathrm{PGD}_{2}$ is active in resolving inflammation [4]. NSAIDs inhibit synthesis of $\mathrm{PGD}_{2}$ and have been shown to delay resolution of experimentally induced inflammation through a mechanism that can be overridden by local administration of exogenous $\mathrm{PGD}_{2}$ $[4,5]$. There are two PGD synthase isozymes. Lipocalin-type PGD synthase is primarily expressed in brain, heart, and adipose tissue, and hematopoietic PGD synthase (hPGDS) is mainly expressed in mast cells, macrophages, dendritic cells (DC), and $\mathrm{Th}_{2}$ lymphocytes [6]. hPGDS appears to be the PGD synthase most involved in resolution of inflammation, since animals that are genetically deficient in hPGDS show impaired resolution of inflammation, and animals transgenic for hPGDS have reduced inflammatory responses [7]. The biological actions for $\mathrm{PGD}_{2}$ are mainly mediated via the $\mathrm{D}$ prostanoid receptors $\mathrm{DP}_{1}$ and $\mathrm{DP}_{2}(\mathrm{CRTH} 2)$ (for reviews, see $[8,9])$.

We have recently shown that dietary fortification with vitamin $\mathrm{D}_{3}$ reduced the severity and duration of adoptively transferred polyarthritis in rats and that the effect was 
associated with reduced expression of PGE synthase and increased expression of hPGDS by DCs from synovium-rich hind paw tissue [10].

$\mathrm{PGE}_{2}$ has been found in rheumatoid synovial fluid (SF) $[11,12]$ with emphasis on its role in inflammation and the effects of NSAIDs. While the potentially anti-inflammatory $\mathrm{PGD}_{2}$ and its nonenzymatic metabolite 15-deoxy $\mathrm{PGJ}_{2}$ have been found in synovial fluid, this prostaglandin has received much less attention $[13,14]$. We have examined chronic joint effusions for the presence of $\mathrm{PGD}_{2}$ and have explored the potential contributions of myeloid $\mathrm{DC}(\mathrm{mDC})$ and monocytes to the intra-articular synthesis of $\mathrm{PGD}_{2}$.

\section{Materials and Methods}

2.1. Subjects. SF and blood samples were obtained from patients undergoing arthrocentesis of chronic inflammatory knee effusions. All patients were ambulatory community dwellers, and, with the exception of two patients, the remainder were known to be vitamin $\mathrm{D}$ replete based on serum 25 -hydroxy-cholecalciferol being $\geq 74 \mathrm{nmol} / \mathrm{L}$, or based on history of regular vitamin D supplementation. While the vitamin $\mathrm{D}$ status in the other two patients was not known, both were active in outdoor pursuits. Diagnostic details and medications taken are shown in Table 1. All patients and healthy donors gave informed consent and the study protocol was approved by the Human Research Ethics Committee, Royal Adelaide Hospital Australia.

2.2. Measurement of Systemic Disease Activity. Systemic disease activity was assessed by routine laboratory testing for erythrocyte sedimentation rate (ESR) and C-reactive protein (CRP).

2.3. $P G D_{2}$ and $P G E_{2}$ Assay. Analysis of $\mathrm{PGD}_{2}$ and $\mathrm{PGE}_{2}$ by ultrahigh-performance liquid chromatography tandem mass spectrometry (UPLC-MS/MS) was undertaken based on the protocol reported by Unterwurzacher et al. [15]. The method enables the resolution of $\mathrm{PGE}_{2}$ and $\mathrm{PGD}_{2}$ with quantification using homologous deuterated internal standards. Unfractionated SF and whole blood samples were applied to purpose-designed filter papers and stored at $-70^{\circ} \mathrm{C}$ until further use. Analysis of $6 \mathrm{~mm}$ punched filter paper spots was extracted with $100 \mu \mathrm{L}$ of acetonitrile: water mixture containing the stable isotopes. A volume of $10 \mu \mathrm{L}$ was injected onto a reversed phase column (ZORBAX Eclipse XDB C18, $3.0 \times 100 \mathrm{~mm}, 3.5 \mu \mathrm{m}$ particle size, Agilent Technologies, Vienna, Austria). The prostanoids were eluted using a gradient of water to $100 \%$ acetonitrile $/ 0.05 \%$ formic acid into a AB Sciex API 5000 QJet triple quadrupole instrument. The concentration of each analyte was determined against the respective stable isotope prostaglandin $\mathrm{D}_{2}-\mathrm{d} 4\left(\mathrm{PGD}_{2}-\mathrm{d} 4\right)$ and prostaglandin $\mathrm{E}_{2}-\mathrm{d} 4\left(\mathrm{PGE}_{2}-\mathrm{d} 4\right)$ from Cayman Europe Chemicals.

2.4. Isolation of Mononuclear Cells from SF and Peripheral Blood (PB). SF and blood samples were collected into heparinised tubes. SF was diluted in RPMI containing $2 \%$ fetal bovine serum (complete medium) prior to centrifugation for 10 minutes at $293 \mathrm{~g}$ [16]. The SF cells were resuspended in complete medium. Resuspended SF cells and blood cells were fractionated by centrifugation on a Lymphoprep density gradient at $600 \mathrm{~g}$ for 30 minutes in order to isolate mononuclear cells. All cell analyses were undertaken on freshly isolated cells.

2.5. Flow Cytometric Analysis. Flow cytometric analysis was performed as described previously [10]. The following antibodies were used: Alexa fluor 488 anti-human CD11b, HLADR PE-cy5, PE-CD11c, PE-CD163, PE-CD14, and APCCD14 (BD Biosciences, San Jose, CA, USA). Relevant isotype controls were used throughout. Labelled cells were analysed with a Beckman Coulter EPICS XL-MCL flow cytometer and Coulter EXPO 32 software (Beckman Coulter, Fullerton, CA, USA).

2.6. Isolation of Myeloid DCs and Monocytes by Flow Cytometry. SF mononuclear cells separated by gradient density were labelled with a cocktail of conjugated mAbs comprising Alexa fluor 488-CD11b, phycoerythrin CD11c, PE-cy5 HLADR, and APC-CD14 for $45 \mathrm{~min}$ at $4^{\circ} \mathrm{C}$ as described previously [10]. Cells were gated by size (Figure 2(a)) and subsequently sorted into CD11b+ HLADR+ CD11c+ CD14- (mDC) and $\mathrm{CD} 11 \mathrm{~b}+\mathrm{HLADR}+\mathrm{CD} 11 \mathrm{c}+\mathrm{CD} 14+$ (monocytes) (Figure 2(e)) populations, using FACS Diva software (Becton Dickinson), as described previously [17]. PB blood mononuclear cells were labelled with PE anti-CD14 mAb followed by separation of CD14+ cells by cell sorter.

2.7. Cytology. Cytospin smears prepared from flow cytometrically sorted cells were fixed and stained as described [18].

2.8. RNA Isolation and Quantitative RT-PCR Analysis of Gene Expression. Total RNA was extracted from flow cytometrically sorted cell populations using the RNeasy Mini Kit (Qiagen, Valencia, CA, USA) according to the manufacturer's instructions. Total RNA was reverse-transcribed to cDNA and amplified using the two-step reverse transcriptionpolymerase chain reaction (RT-PCR) kit from Qiagen. RNA and cDNA quality was assessed using a NanoDrop 1000 spectrophotometer (ThermomFisher Scientific, Wil ington, $\mathrm{DE}, \mathrm{USA}$ ) before samples were frozen at $-70^{\circ} \mathrm{C}$ until further use. Gene expression levels were investigated using commercially available specific primers for human genes obtained from Qiagen including hPGDS (QT-00022043), PGES (QT00208607), DP 1 (QT-00036190), and DP 2 (QT-00042448). Real-time PCR was performed using the QuantiFast SYBR Green PCR kit (Qiagen) according to the supplier's protocol, in a Rotor-Gene 3000 real-time PCR machine (Corbett Research, NSW, Australia). A minimum of three replicates of each sample was amplified in all experiments. Each PCR had a sample prepared without template and a sample prepared without primers, serving as negative controls. The reactions were incubated at $95^{\circ} \mathrm{C}$ for $5 \mathrm{~min}$ followed by 35 cycles of $95^{\circ} \mathrm{C}$ for $10 \mathrm{~s}$ and $60^{\circ} \mathrm{C}$ for $30 \mathrm{~s}$. PCR product quality was monitored using post-PCR melt curve analysis. Fold changes 
TABLE 1: Demographic and clinical characteristics of patients.

\begin{tabular}{|c|c|c|c|c|}
\hline Diagnosis & Age (years) & Sex (years) & Disease duration & Treatment \\
\hline RA & 83 & $\mathrm{~F}$ & 18 & DMARDs + NSAIDs + vitD + fish oil \\
\hline RA & 53 & $\mathrm{~F}$ & 3 & DMARDs + NSAIDs + fish oil \\
\hline RA & 82 & $\mathrm{~F}$ & 30 & DMARDs + vitD + fish oil \\
\hline RA & 48 & $\mathrm{~F}$ & 22 & DMARDs + NSAIDs + fish oil \\
\hline RA & 61 & $\mathrm{~F}$ & 13 & Tocilizumab + fish oil \\
\hline RA & 57 & $\mathrm{~F}$ & 27 & DMARDs + Adalimumab + fish oil \\
\hline RA & 60 & $\mathrm{~F}$ & 38 & DMARDs + vitD + fish oil \\
\hline RA & 62 & $\mathrm{~F}$ & 2 & NSAIDs \\
\hline RA & 82 & $\mathrm{~F}$ & 11 & DMARDs + fish oil \\
\hline RA & 50 & $\mathrm{~F}$ & 1 & DMARDs + vitD + fish oil \\
\hline RA & 66 & $\mathrm{~F}$ & 10 & DMARDs + vitD \\
\hline RA & 67 & $\mathrm{~F}$ & 29 & DMARDs + vitD \\
\hline $\mathrm{RNP}^{+}$polyarthritis & 55 & $\mathrm{~F}$ & 3 & DMARDs + NSAIDs + vitD + fish oil \\
\hline $\mathrm{B} 27^{+}$Pauci-arthritis & 35 & $\mathrm{~F}$ & 18 & DMARDs + vitD + fish oil \\
\hline Psoriatic arthritis & 58 & $\mathrm{~F}$ & 6 & DMARDs + vitD + fish oil \\
\hline Psoriatic arthritis & 55 & $\mathrm{~F}$ & 2 & Fish oil \\
\hline $\mathrm{B}^{2} 7^{+}$spondyloarthritis & 62 & M & 41 & DMARDs + NSAIDs + fish oil \\
\hline Juvenile onset-monoarthritis & 34 & $\mathrm{~F}$ & 26 & NSAIDs \\
\hline Crohn's arthritis & 46 & $\mathrm{~F}$ & 30 & DMARDs + vitD \\
\hline Crohn's arthritis & 70 & $\mathrm{~F}$ & 13 & DMARDs + NSAIDs + vitD + fish oil \\
\hline
\end{tabular}

RA: rheumatoid arthritis; DMARDs: disease-modifying anti-inflammatory drugs; NSAIDs: nonsteroidal anti-inflammatory drugs.

were calculated using the formula $2^{-(\Delta \mathrm{Ct})}$, where $\Delta \mathrm{Ct}=\mathrm{Ct}$ (target gene) - Ct ( $\beta$-actin) [19].

2.9. Statistical Analysis. All data were analyzed using GraphPad Prism V5.0 (GraphPad Software, Inc., San Diego, CA, USA). Quantitative real-time RT-PCR signals were normalized to $\beta$-actin. One-way analysis of variance (ANOVA) with Newman-Keuls post hoc test was used to determine significant differences between groups. C-reactive protein (CRP) and ESR correlation to hPGDS expression by SF mDC was analysed by Pearson's correlation. $P<0.05$ was considered statistically significant.

\section{Results}

3.1. $P G D_{2}$ and $P G E_{2}$ in Inflammatory Synovial Fluid. There were similar concentrations of $\mathrm{PGD}_{2}$ and $\mathrm{PGE}_{2}$ in whole blood (Figure 1) whereas the concentration of $\mathrm{PGD}_{2}$ was substantially greater than that of $\mathrm{PGE}_{2}$ in knee effusions from patients with inflammatory arthropathies $(P<0.01)$ (Figure 1).

3.2. Expression of hPGD and PGE Synthases by Myeloid Dendritic Cells (mDCs) and Monocytes Isolated from Synovial Fluid. Populations of mononuclear cells in SF were characterised by three- and four-colour flow cytometry. The forward light scatter gate was chosen (Figure 2(a)) to exclude most lymphocytes and neutrophils and to include monocytes, macrophages, and DCs. CD11b antibody, which detects myeloid haematopoietic cells, stained about half of the cells in this gate. The CD11b stained cells comprised a single

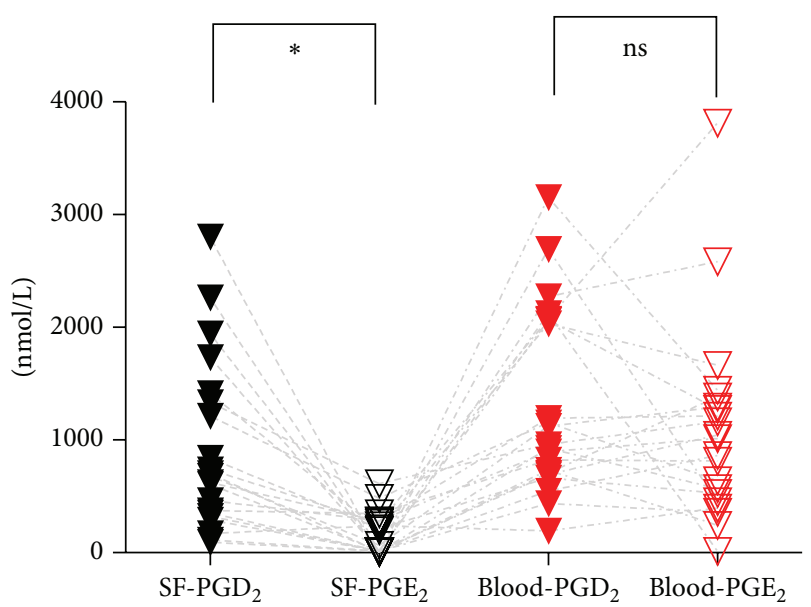

FIGURE 1: Concentrations of $\mathrm{PGD}_{2}$ and $\mathrm{PGE}_{2}$ in synovial fluid and whole blood. Lines connect results from the same person. ${ }^{*} P<0.01$; ns: not significant.

peak of fluorescence, which was well resolved from unlabelled cells (Figure 2(b)). About $80 \%$ of the CD11b+ HLADR+ cells in SF expressed CD11c (Figure 2(c)), consistent with their designation as monocytes or $\mathrm{mDC}$. The minority population (20\%) of CD11b+ HLADR+ cells appeared to be macrophages as evinced by proportionate staining for the macrophage marker CD163+ (Figure 2(d)). Based on CD14 staining in four-colour flow cytometric (Figure 2(e)) and cytospin analyses (Figures 2(f) and 2(g)), the CD11b+ HLADR+ CD11c+ cells were separated into $\mathrm{mDC}(5 \%)$ (CD14-, Figure 2(e); 


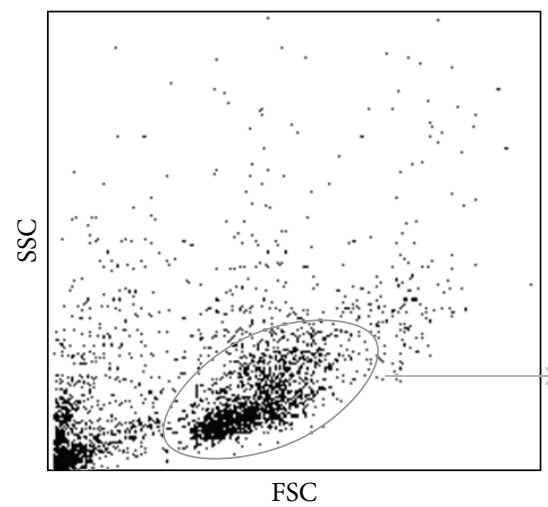

(a)

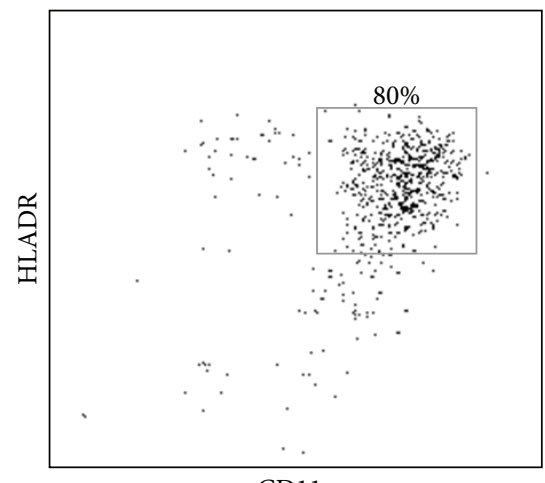

CD11c

(c)

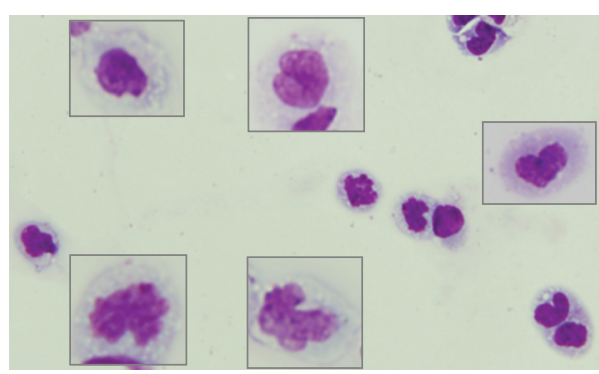

(f)

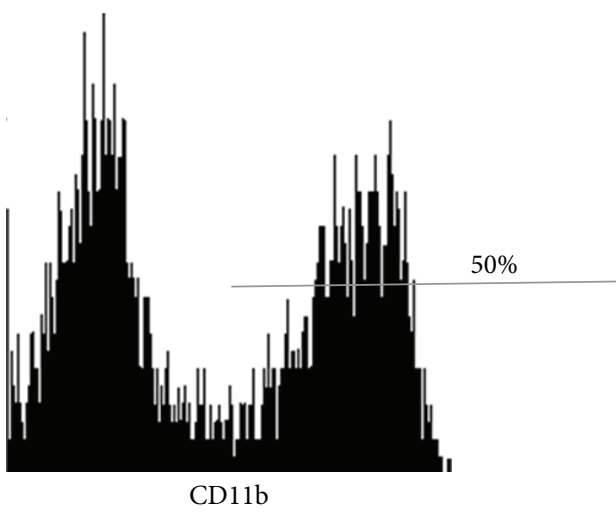

(b)

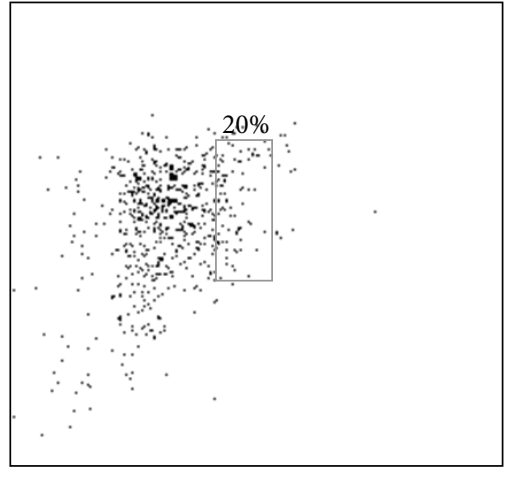

CD163

(d)

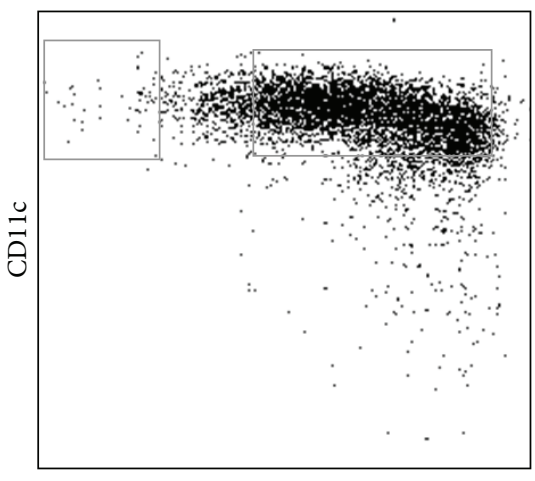

CD14

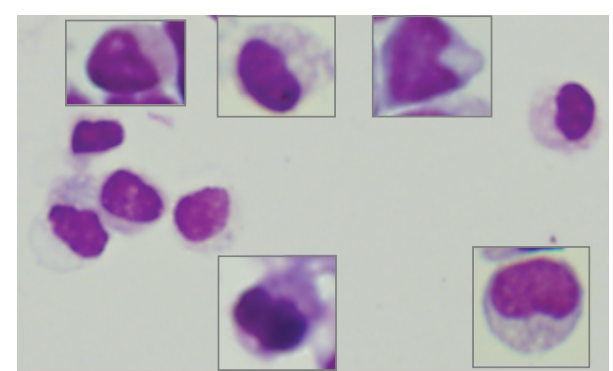

(g)

FIGURE 2: Flow cytometric analysis of cells prepared from SF aspirates. (a) Shows the selected gate based on forward and side scatter of light. (b) Shows CD11b staining of 50\% of SF cells in a single peak. (c) Shows 3-colour flow cytometric analysis in which 80\% of CD11b+ HLADR+ SF cells express CD11c. (d) Shows 3-colour analysis of SF cells in which 20\% of CD11b+ HLADR+ cells express CD163. (e) Shows 4-colour analysis to separate CD14- from CD14+ subsets of HLADR+ CD11b+ CD11c+ cells. The CD14- cells were enriched for cells with DC morphology (f), whereas the CD14+ subpopulation displayed monocyte morphology (g).

DC morphology, Figure 2(f)) and monocytes (75\%) (CD14+, Figure 2(e); monocyte morphology, Figure 2(g)).

The expression of mRNA for hPGDS by SF mDC was greater in SF mDC than in SF monocytes $(P<0.0001)$ or peripheral blood monocytes $(P<0.0001)$ (Figure 3(a)). mRNA for the PGD receptor $\mathrm{DP}_{2}$ was increased in SF $\mathrm{mDC}$ and peripheral blood monocytes compared with SF monocytes (Figure 3(b)). Minimal mRNA expression of enzymes $\mathrm{COX}_{1}$ or $\mathrm{COX}_{2}$ (data not shown) or the potentially competing terminal synthase PGES (Figure 3(c)) was detected in SF mDC and monocytes. As shown in Figure 3(d), in SF mDC expression of hPGDS was significantly $(P<0.05)$ higher than PGES.

3.3. $P G D_{2}$ Expression and Disease Activity. The higher level of $\mathrm{PGD}_{2}$ in synovial fluid and higher expression of hPGDS by $\mathrm{SF} \mathrm{mDC}$ seen in some patients was intriguing and led us to explore a possible correlation with inflammatory disease activity (Figure 4). CRP and ESR levels were inversely correlated with synovial fluid concentration of $\mathrm{PGD}_{2}$ and synovial fluid mDC expression of hPGDS (Figure 4). 


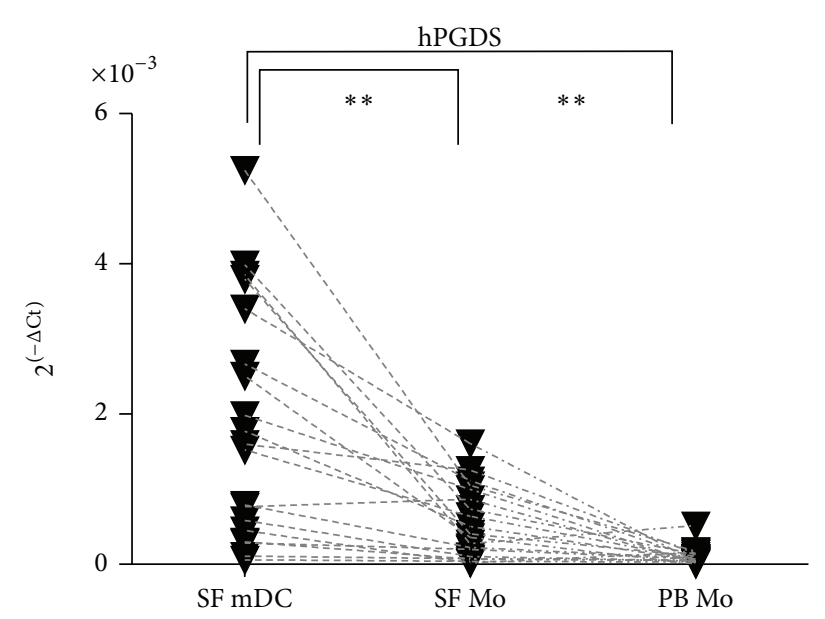

(a)

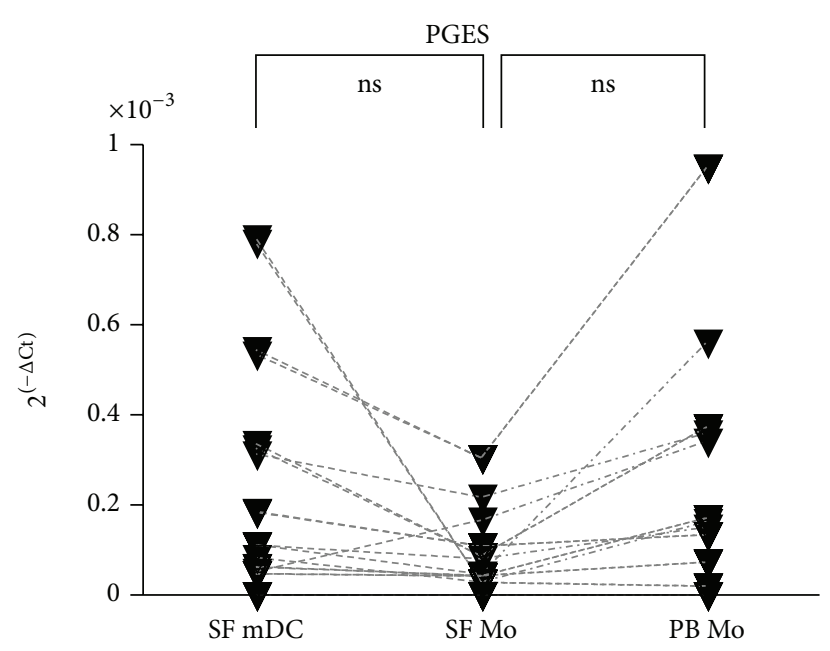

(c)

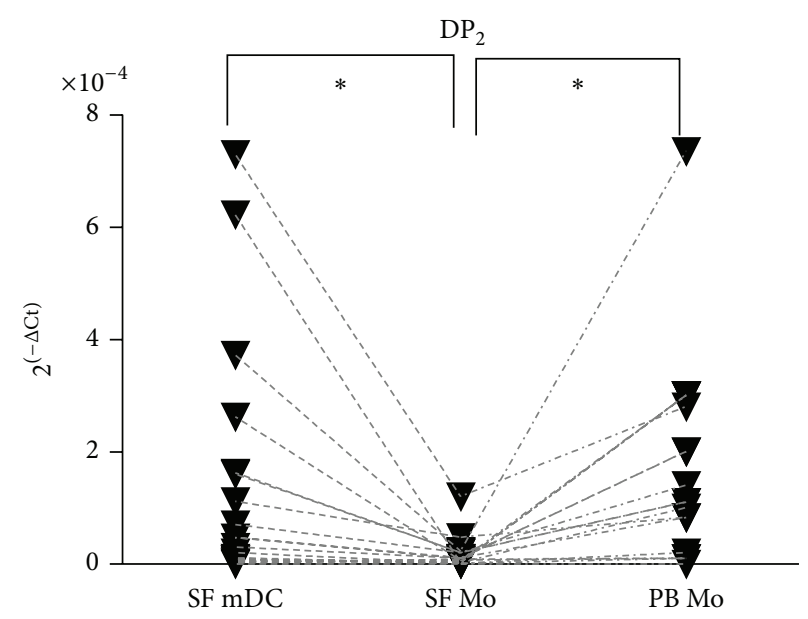

(b)

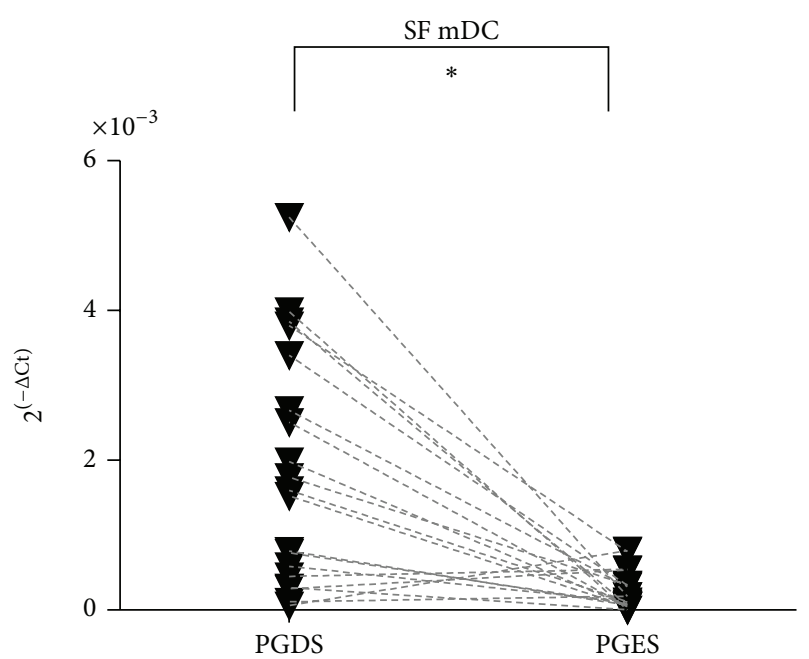

(d)

FIGURE 3: Expression of mRNA for (a) hPGDS, (b) PGD receptor DP 2 , (c) PGES in SF myeloid DC, SF monocytes, and PB monocytes, and (d) hPGDS versus PGES in SF mDC in patients with inflammatory arthritis. ${ }^{*} P<0.01,{ }^{* *} P<0.0001$, ns: not significant.

\section{Discussion}

The progression from acute to chronic inflammation has been viewed as a persistence of excess proinflammatory mediators, but more recent studies show that it may also arise from a failure of mechanisms that resolve inflammation [20]. Although mononuclear cells can in many settings contribute to proinflammatory responses, they are also critical in tissue repair in a noninflammatory manner [21]. Most successful inflammatory processes are self-limiting, which implies the existence of endogenous anti-inflammation pathways [22].

A number of mediators, including $\mathrm{PGD}_{2}$, have been shown to actively promote resolution of inflammation [22, 23]. PGDS knockout mice had impaired resolution of inflammation whereas PGDS transgenic mice had reduced inflammatory responses [7]. $\mathrm{PGD}_{2}$ suppresses joint inflammation in murine collagen-induced arthritis [24]. We have shown that dietary fortification with vitamin D3 reduced the severity and duration of adoptively transferred polyarthritis (ATA) in rats, and this was associated with increased expression of hPGDS and reduced expression of PGES by $\mathrm{mDC}$ from synoviumrich hind paw tissue of arthritic rats [10]. The source of SF $\mathrm{PGD}_{2}$ probably involves cells other than SF mDCs. Mast cells contain PGDS and anti-IgE stimulates $\mathrm{PGD}_{2}$ synthesis in human and rat mast cells [25]. However, antigen presenting cells including DC were the major source of hPGDS in various rat tissues even though there was expression in mast cells [26]. In human skin, all of the antigen presenting cells express hPGDS, and this includes Langerhans cells, dermal DCs, and plasmacytoid and myelocytic DCs. The authors reporting these observations acknowledge that mast cells produce $\mathrm{PGD}_{2}$ but conclude that epidermal DCs such as Langerhans cells should be a major source of $\mathrm{PGD}_{2}$ in skin at least [27]. While there appear to be no prior reports linking SF mDCs to production of $\mathrm{PGD}_{2}$, monocyte-derived DCs have been shown to produce $\mathrm{PGD}_{2}$ [27].

In the present study, we observed that SF from patients with inflammatory arthritis contains significantly greater 

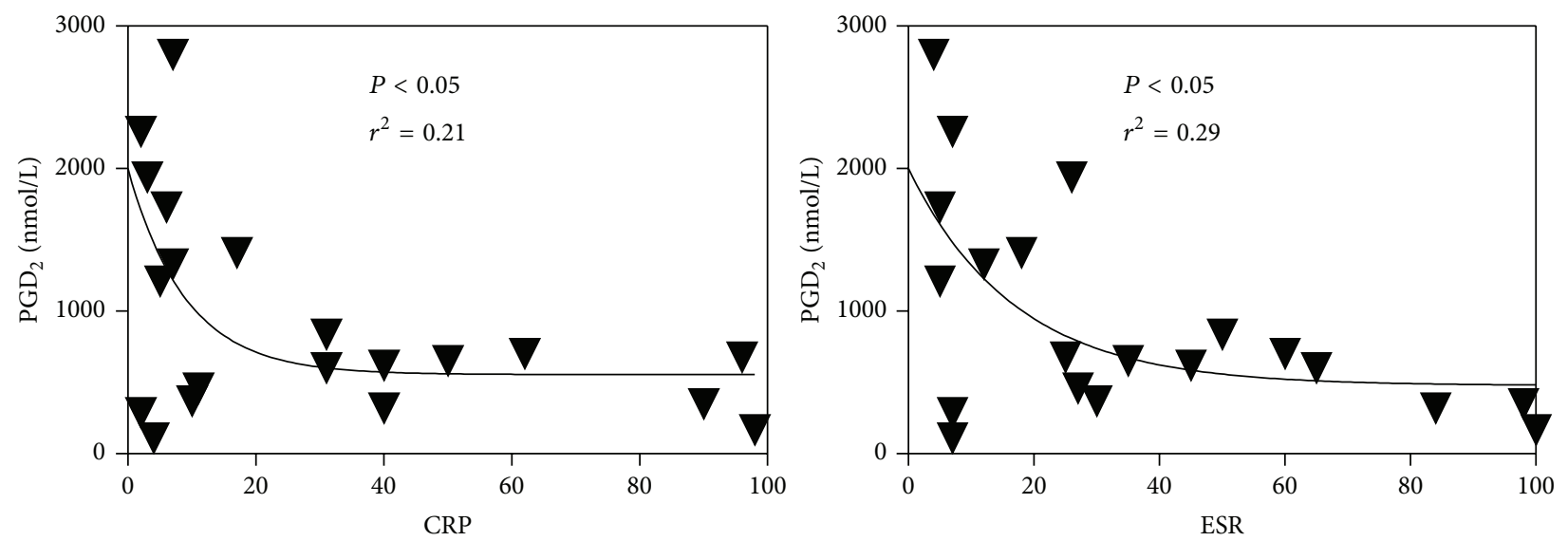

(a)
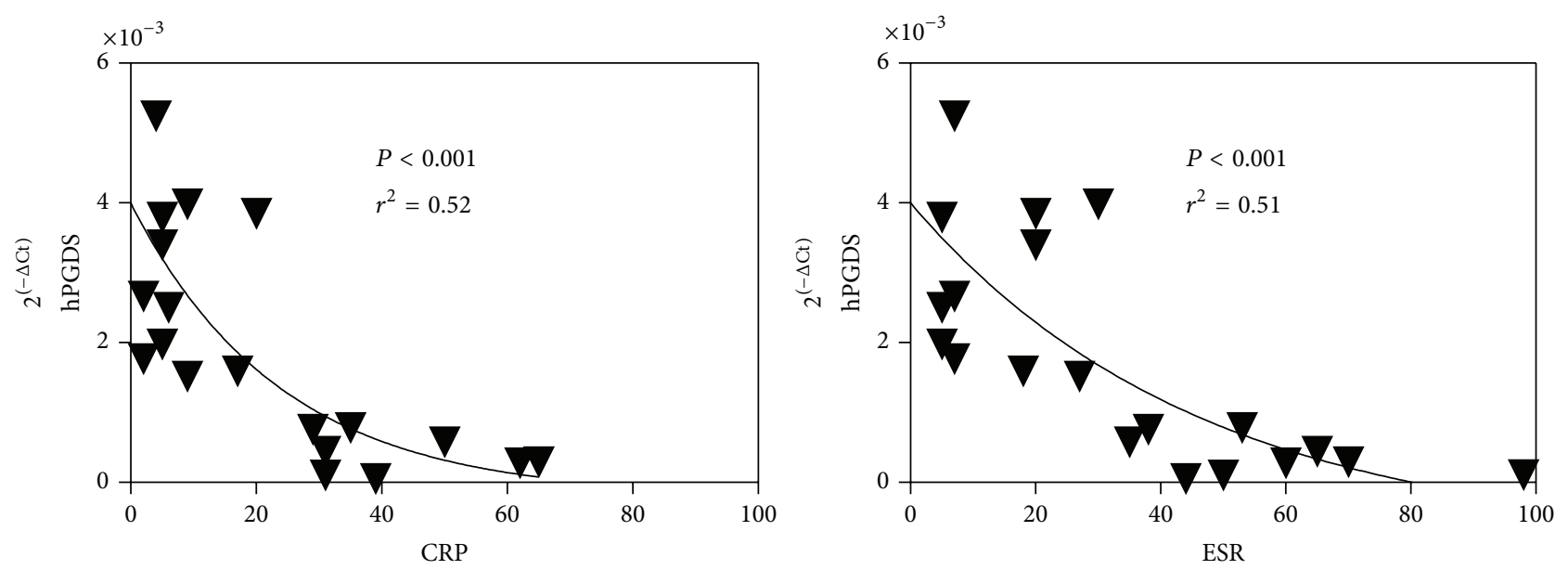

(b)
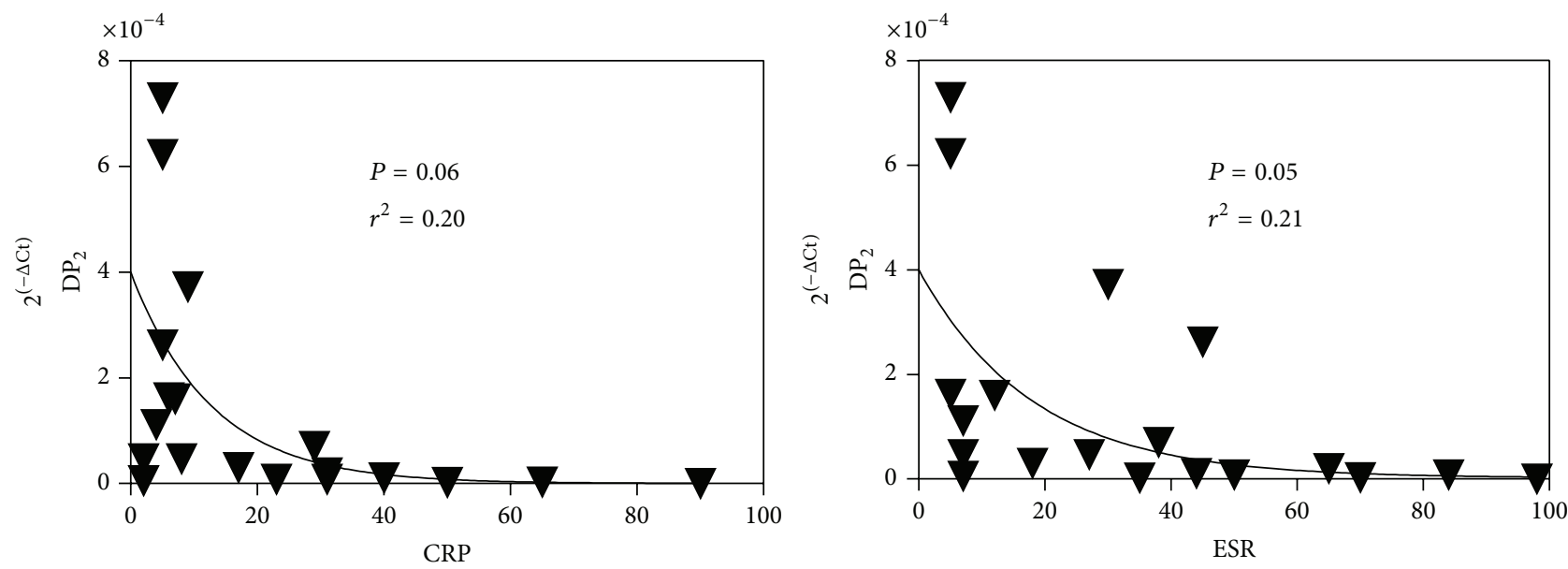

(c)

FIGURE 4: Pearson's correlations between systemic disease activity measured by CRP or ESR and (a) synovial concentrations of PGD ${ }_{2}$, and synovial $\mathrm{mDC}$ expression of (b) hPGDS and (c) $\mathrm{DP}_{2}$ receptor.

levels of $\mathrm{PGD}_{2}$ than $\mathrm{PGE}_{2}$. SF mDCs were found to express significantly more hPGDS than PGES. PGD $_{2}$ may affect various immune cells and effector cells, including mDCs themselves through the $\mathrm{DP}_{2}$ receptor, which we found is more strongly expressed in SF mDCs and $\mathrm{PB}$ monocytes than in $\mathrm{SF}$ monocytes. Exogenous $\mathrm{PGD}_{2}$ and its nonenzymatic metabolite 15 -deoxy $\Delta 12,14 \mathrm{PGJ}_{2}\left(15 \mathrm{~d}-\mathrm{PGJ}_{2}\right)$ has the ability to modulate the function and maturation of monocyte-derived 
DC $[28,29]$. While $15 \mathrm{~d}-\mathrm{PGJ}_{2}$ can interact with the $\mathrm{DP}_{2}$ receptor, there is longstanding controversy as to whether it is an endogenous mediator, especially of $\operatorname{PPAR} \gamma$, due to its very low levels in vivo [30]. Factors which enhance the expression of PGD synthase should have useful anti-inflammatory effect. The participants in this study were replete in vitamin D which we have shown to upregulate joint mDC hPGDS in rat polyarthritis [10].

There were no significant differences in the expression of PGES between SF mDCs or SF or peripheral blood monocytes. Both SF mDCs and monocytes expressed little COX2 constitutively, although we have observed that COX2 expression is significantly upregulated by these cells in response to LPS stimulation (data not shown). As mentioned above, SF mDCs expressed significantly lower level of PGES than PGDS. It is possible that the anti-inflammatory treatments applied may have influenced PGES expression [31, 32]. Our practice is to advise patients to avoid NSAIDs in favour of an anti-inflammatory dose of fish oil and to use NSAIDs sparing as needed for 2nd-line analgesia on grounds of safety and the lack of a favourable disease modifying effect with NSAIDs use. On mechanistic grounds, one might expect regular, more intensive NSAIDs use to yield symptomatic benefit from reduced $\mathrm{PGE}_{2}$ synthesis achieved through the reduction of the precursor COX-2 product $\mathrm{PGH}_{2}$, which is the substrate for both PGES and PGDS. However, a concomitant reduction in $\mathrm{PGD}_{2}$ synthesis would be expected to compromise disease control and resolution. While conventional and biological disease modifying antirheumatic drugs (DMARDs) may conceivably influence the production of PG, the effects are likely indirect. The issue has been most thoroughly investigated with methotrexate with conflicting findings [33-35].

hPGDS and its products $\mathrm{PGD}_{2}$ and further downstream metabolites 15 -deoxy $\Delta 12,14 \mathrm{PGJ}_{2}\left(15-\mathrm{PGJ}_{2}\right)$ are clearly involved in resolution of inflammation, acting on cell traffic and cytokine synthesis in animal models $[5,7,36]$. Colonic mucosal synthesis of $\mathrm{PGD}_{2}$, which is specifically upregulated during remission from ulcerative colitis, may contribute to the maintenance of remission in these patients [37]. The finding of hPGDS in human synovial $\mathrm{mDC}$ as well as $\mathrm{PGD}_{2}$ in synovial fluid and the inverse relation to disease activity prompts the question of whether mediators present in inflamed joints are inducers of hPGDS in human SF DCs. If so, suppression of the synthesis or action of these mediators by NSAIDs may suppress the development of the natural resolution phase of inflammation.

In conclusion, the findings indicate that synovial mDCs exhibit expression characteristics appropriate for an active role in $\mathrm{PGD}_{2}$ synthesis and that $\mathrm{PGD}_{2}$ is present in inflammatory effusions. The inverse correlation of both $\mathrm{PGD}_{2}$ and expression of hPGDS in mDCs in SF with the markers of systemic disease activity (CRP and ESR) suggests that systemic disease activity may be influenced by actions of $\mathrm{PGD}_{2}$ in rheumatoid arthritis and other arthropathies. Within this small sample of patients, most of whom had rheumatoid arthritis, this putative effect was not obviously influenced by the type of arthropathy or DMARD therapy. It remains to be determined if the elevated PGDS in SF mDCs and $\mathrm{PGD}_{2}$ in $\mathrm{SF}$ observed in patients who had low CRP and ESR contributes to remission in RA group of patients.

\section{Acknowledgments}

This work was funded in part by Arthritis Foundation of Australia, Grant-in-Aid, 2011. The authors are grateful to Mr. Alan Bishop for his advice and assistance with flow cytometry and cell sorting and Drs Melissa Gregory and Rebecca CookJohnson for valuable advice in RT-PCR analysis.

\section{References}

[1] W. L. Smith, "Nutritionally essential fatty acids and biologically indispensable cyclooxygenases," Trends in Biochemical Sciences, vol. 33, no. 1, pp. 27-37, 2008.

[2] C. E. Trebino, J. L. Stock, C. P. Gibbons et al., "Impaired inflammatory and pain responses in mice lacking an inducible prostaglandin E synthase," Proceedings of the National Academy of Sciences of the United States of America, vol. 100, no. 15, pp. 9044-9049, 2003.

[3] J. R. Vane and R. M. Botting, "Anti-inflammatory drugs and their mechanism of action," Inflammation Research, vol. 47, supplement 2, pp. S78-S87, 1998.

[4] O. Haworth and C. D. Buckley, "Resolving the problem of persistence in the switch from acute to chronic inflammation," Proceedings of the National Academy of Sciences of the United States of America, vol. 104, no. 52, pp. 20647-20648, 2007.

[5] R. Rajakariar, M. Hilliard, T. Lawrence et al., "Hematopoietic prostaglandin $\mathrm{D}_{2}$ synthase controls the onset and resolution of acute inflammation through $\mathrm{PGD}_{2}$ and 15 -deoxy $\Delta^{12--14} \mathrm{PGJ}_{2}$," Proceedings of the National Academy of Sciences of the United States of America, vol. 104, no. 52, pp. 20979-20984, 2007.

[6] M. Arima and T. Fukuda, "Prostaglandin $\mathrm{D}_{2}$ and $\mathrm{T}_{H} 2$ inflammation in the pathogenesis of bronchial asthma," The Korean Journal of Internal Medicine, vol. 26, no. 1, pp. 8-18, 2011.

[7] S. G. Trivedi, J. Newson, R. Rajakariar et al., "Essential role for hematopoietic prostaglandin $\mathrm{D}_{2}$ synthase in the control of delayed type hypersensitivity," Proceedings of the National Academy of Sciences of the United States of America, vol. 103, no. 13, pp. 5179-5184, 2006.

[8] E. Kostenis and T. Ulven, "Emerging roles of DP and CRTH2 in allergic inflammation," Trends in Molecular Medicine, vol. 12, no. 4, pp. 148-158, 2006.

[9] F. Trottein, C. Faveeuw, P. Gosset, and V. Angeli, "Role of the $\mathrm{D}$ prostanoid receptor 1 in the modulation of immune and inflammatory response," Critical Reviews in Immunology, vol. 24, no. 5, pp. 349-362, 2004.

[10] M. Moghaddami, G. Mayrhofer, P. H. Anderson, H. A. Morris, M. Van Der Hoek, and L. G. Cleland, "Efficacy and mechanisms of action of vitamin D in experimental polyarthritis," Immunology and Cell Biology, vol. 90, no. 2, pp. 168-177, 2012.

[11] J. Akaogi, T. Nozaki, M. Satoh, and H. Yamada, "Role of PGE2 and EP receptors in the pathogenesis of rheumatoid arthritis and as a novel therapeutic strategy," Endocrine, Metabolic and Immune Disorders, vol. 6, no. 4, pp. 383-394, 2006.

[12] D. O. Stichtenoth, S. Thorén, H. Bian, M. Peters-Golden, P. J. Jakobsson, and L. J. Crofford, "Microsomal prostaglandin E synthase is regulated by proinflammatory cytokines and glucocorticoids in primary rheumatoid synovial cells," The Journal of Immunology, vol. 167, no. 1, pp. 469-474, 2001. 
[13] D. Egg, "Concentrations of prostaglandins D2, E2, F2 alpha, 6-keto-F1 alpha and thromboxane B2 in synovial fluid from patients with inflammatory joint disorders and osteoarthritis," Zeitschrift fur Rheumatologie, vol. 43, no. 2, pp. 89-96, 1984.

[14] Z. Z. Shan, K. Masuko-Hongo, S. M. Dai, H. Nakamura, T. Kato, and K. Nishioka, "A potential role of 15 -deoxy- $\Delta^{12,14}$ prostaglandin $\mathrm{J} 2$ for induction of human articular chondrocyte apoptosis in arthritis," The Journal of Biological Chemistry, vol. 279, no. 36, pp. 37939-37950, 2004.

[15] I. Unterwurzacher, T. Koal, G. K. Bonn, K. M. Weinberger, and S. L. Ramsay, "Rapid sample preparation and simultaneous quantitation of prostaglandins and lipoxygenase derived fatty acid metabolites by liquid chromatography-mass spectrometry from small sample volumes," Clinical Chemistry and Laboratory Medicine, vol. 46, no. 11, pp. 1589-1597, 2008.

[16] M. Moghaddami, L. G. Cleland, and G. Mayrhofer, "MHC $\mathrm{II}^{+} \mathrm{CD} 45^{+}$cells from synovium-rich tissues of normal rats: phenotype, comparison with macrophage and dendritic cell lineages and differentiation into mature dendritic cells in vitro," International Immunology, vol. 17, no. 8, pp. 1103-1115, 2005.

[17] M. Moghaddami, G. Mayrhofer, and L. G. Cleland, "MHC class II compartment, endocytosis and phagocytic activity of macrophages and putative dendritic cells isolated from normal tissues rich in synovium," International Immunology, vol. 17, no. 8, pp. 1117-1130, 2005.

[18] M. Moghaddami, L. G. Cleland, G. Radisic, and G. Mayrhofer, "Recruitment of dendritic cells and macrophages during T cellmediated synovial inflammation," Arthritis Research \& Therapy, vol. 9, no. 6, article R120, 2007.

[19] T. D. Schmittgen and K. J. Livak, "Analyzing real-time PCR data by the comparative $\mathrm{C}_{T}$ method," Nature Protocols, vol. 3, no. 6 , pp. 1101-1108, 2008.

[20] C. N. Serhan, "The resolution of inflammation: the devil in the flask and in the details," The FASEB Journal, vol. 25, no. 5, pp. 1441-1448, 2011.

[21] M. J. Stables, S. Shah, E. B. Camon et al., "Transcriptomic analyses of murine resolution-phase macrophages," Blood, vol. 118, no. 26, pp. e192-e208, 2011.

[22] C. N. Serhan and J. Savill, "Resolution of inflammation: the beginning programs the end," Nature Immunology, vol. 6, no. 12, pp. 1191-1197, 2005.

[23] D. W. Gilroy, T. Lawrence, M. Perretti, and A. G. Rossi, "Inflammatory resolution: new opportunities for drug discovery," Nature Reviews Drug Discovery, vol. 3, no. 5, pp. 401-416, 2004.

[24] N. Maicas, L. Ibanez, M. J. Alcaraz, A. Ubeda, and M. L. Ferrandiz, "Prostaglandin $\mathrm{D}_{2}$ regulates joint inflammation and destruction in murine collagen-induced arthritis," Arthritis \& Rheumatism, vol. 64, no. 1, pp. 130-140, 2012.

[25] R. A. Lewis, N. A. Soter, P. T. Diamond et al., "Prostaglandin $\mathrm{D}_{2}$ generation after activation of rat and human mast cells with anti-IgE," The Journal of Immunology, vol. 129, no. 4, pp. 16271631, 1982.

[26] Y. Urade, M. Ujihara, Y. Horiguchi, K. Ikai, and O. Hayaishi, "The major source of endogenous prostaglandin $\mathrm{D}_{2}$ production is likely antigen-presenting cells. Localization of glutathionerequiring prostaglandin $\mathrm{D}$ synthetase in histiocytes, dendritic, and Kupffer cells in various rat tissues," The Journal of Immunology, vol. 143, no. 9, pp. 2982-2989, 1989.

[27] C. Shimura, T. Satoh, K. Igawa et al., "Dendritic cells express hematopoietic prostaglandin D synthase and function as a source of prostaglandin $\mathrm{D}_{2}$ in the skin," American Journal of Pathology, vol. 176, no. 1, pp. 227-237, 2010.

[28] P. Gosset, F. Bureau, V. Angeli et al., "Prostaglandin $\mathrm{D}_{2}$ affects the maturation of human monocyte-derived dendritic cells: consequence on the polarization of naive Th cells," The Journal of Immunology, vol. 170, no. 10, pp. 4943-4952, 2003.

[29] P. Gosset, M. Pichavant, C. Faveeuw, F. Bureau, A. B. Tonnel, and F. Trottein, "Prostaglandin $\mathrm{D}_{2}$ affects the differentiation and functions of human dendritic cells: impact on the $\mathrm{T}$ cell response," European Journal of Immunology, vol. 35, no. 5, pp. 1491-1500, 2005.

[30] W. S. Powell, "15-deoxy- $\Delta^{12,14}-\mathrm{PGJ}_{2}$ : endogenous PPAR $\gamma$ ligand or minor eicosanoid degradation product?" The Journal of Clinical Investigation, vol. 112, no. 6, pp. 828-830, 2003.

[31] L. J. Crofford, "Clinical experience with specific COX-2 inhibitors in arthritis," Current Pharmaceutical Design, vol. 6, no. 17, pp. 1725-1736, 2000.

[32] B. M. Kirsch, M. Zeyda, K. Stuhlmeier et al., "The active metabolite of leflunomide, A77 1726, interferes with dendritic cell function," Arthritis Research \& Therapy, vol. 7, no. 3, pp. R694-R703, 2005.

[33] P. Vergne, B. Liagre, P. Bertin et al., "Methotrexate and cyclooxygenase metabolism in cultured human rheumatoid synoviocytes," Journal of Rheumatology, vol. 25, no. 3, pp. 433440, 1998.

[34] M. Seitz, P. Loetscher, B. Dewald, H. Towbin, and M. Baggiolini, "In vitro modulation of cytokine, cytokine inhibitor, and prostaglandin E release from blood mononuclear cells and synovial fibroblasts by antirheumatic drugs," Journal of Rheumatology, vol. 24, no. 8, pp. 1471-1476, 1997.

[35] K. R. Gheorghe, S. Sadique, P. Leclerc, " et al., "Limited effect of anti-rheumatic treatment on 15-prostaglandin dehydrogenase in rheumatoid arthritis synovial tissue," Arthritis Research and Therapy, vol. 14, no. 3, article R121, 2012.

[36] D. W. Gilroy, P. R. Colville-Nash, D. Willis, J. Chivers, M. J. PaulClark, and D. A. Willoughby, "Inducible cyclooxygenase may have anti-inflammatory properties," Nature Medicine, vol. 5, no. 6, pp. 698-701, 1999.

[37] L. Vong, J. G. P. Ferraz, R. Panaccione, P. L. Beck, and J. L. Wallace, "A pro-resolution mediator, prostaglandin $\mathrm{D}_{2}$, is specifically up-regulated in individuals in long-term remission from ulcerative colitis," Proceedings of the National Academy of Sciences of the United States of America, vol. 107, no. 26, pp. 12023-12027, 2010. 


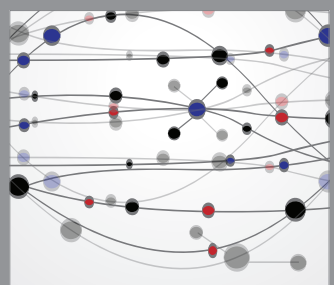

The Scientific World Journal
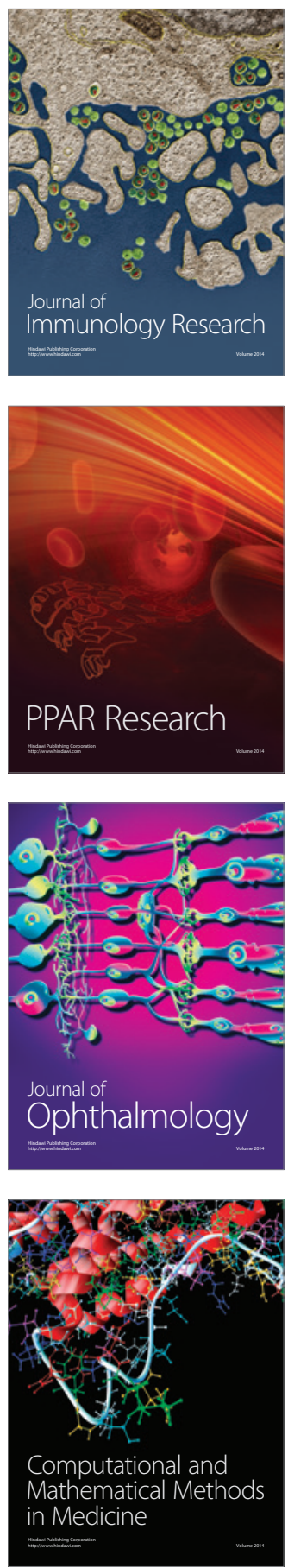

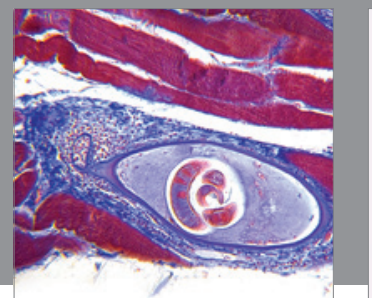

Gastroenterology

Research and Practice
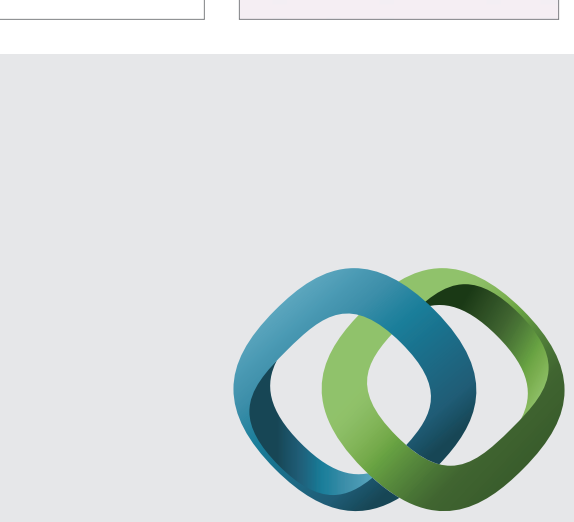

\section{Hindawi}

Submit your manuscripts at

http://www.hindawi.com
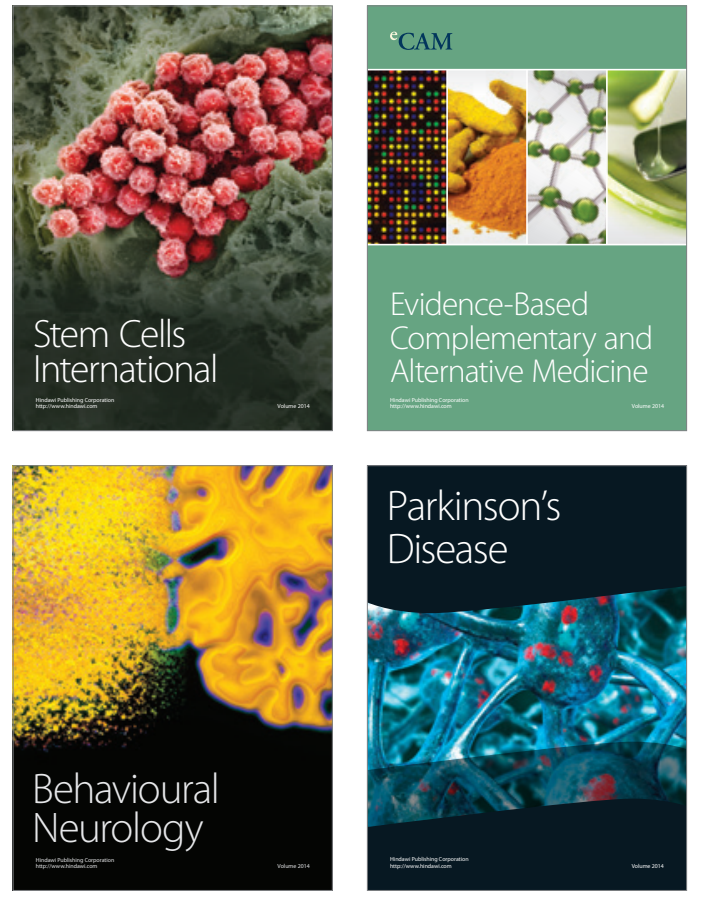
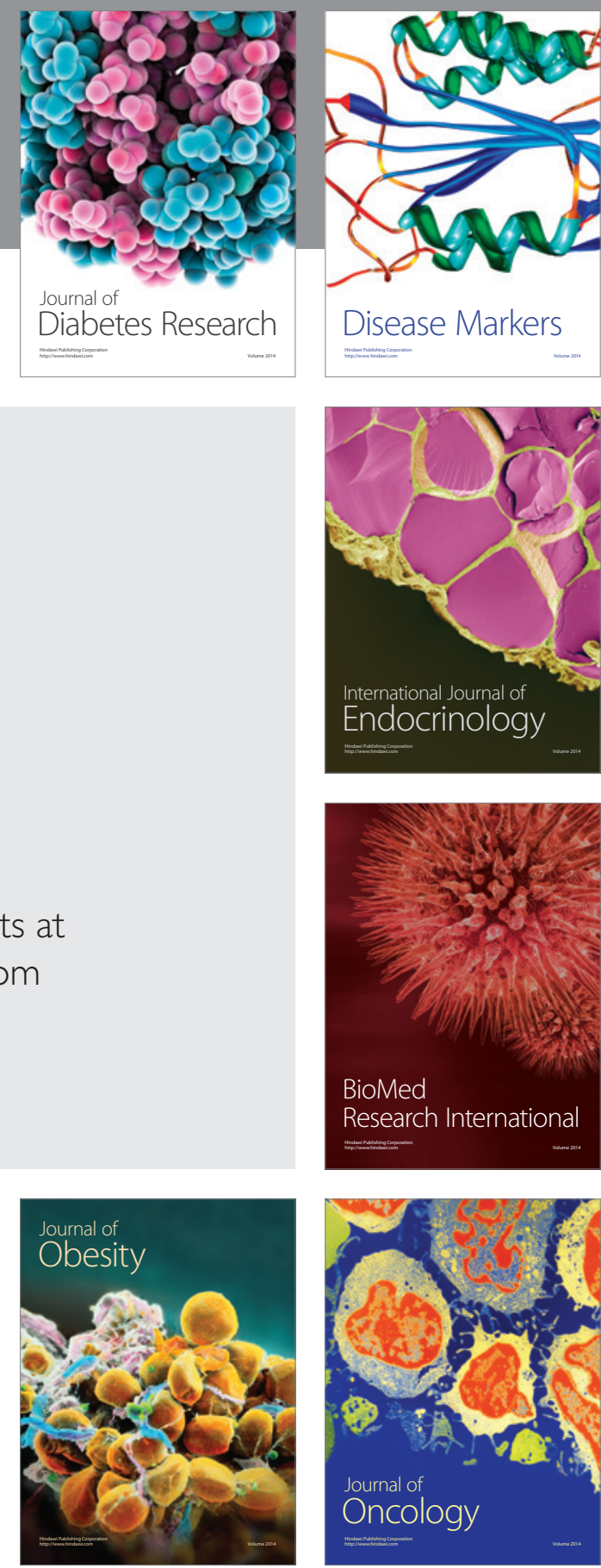

Disease Markers
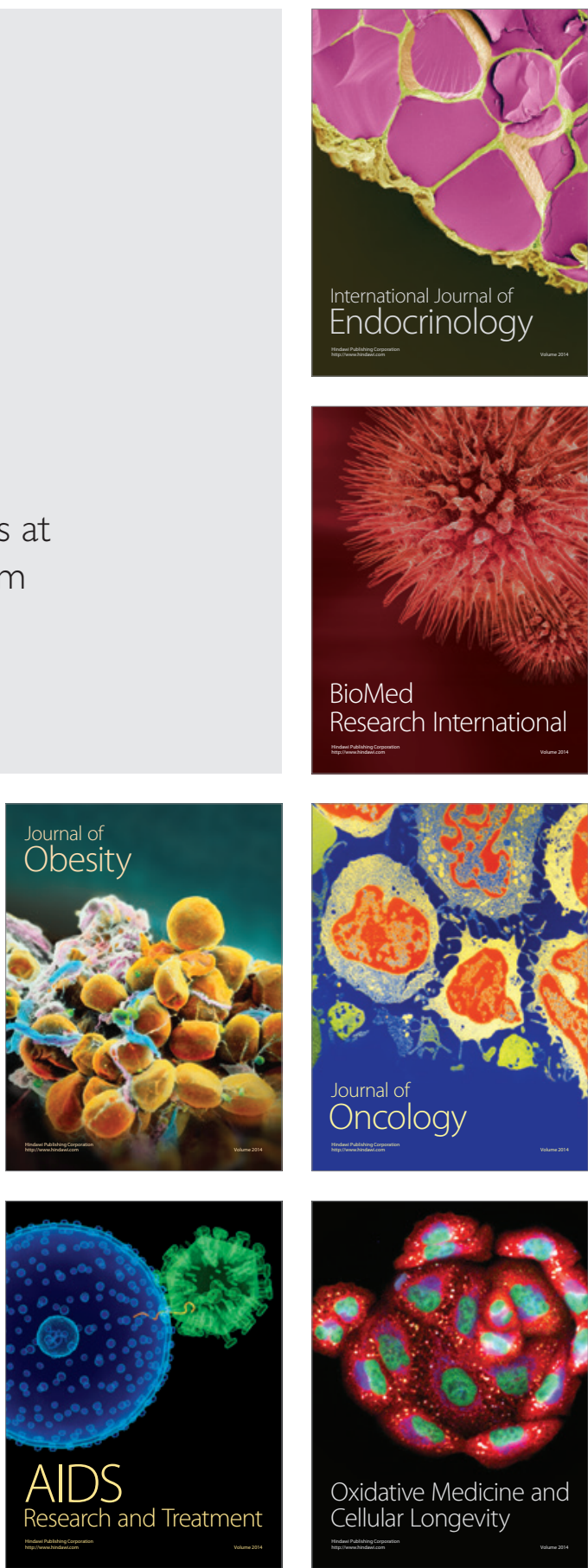